\title{
From Newton to Rutherford: British scientists in oils
}
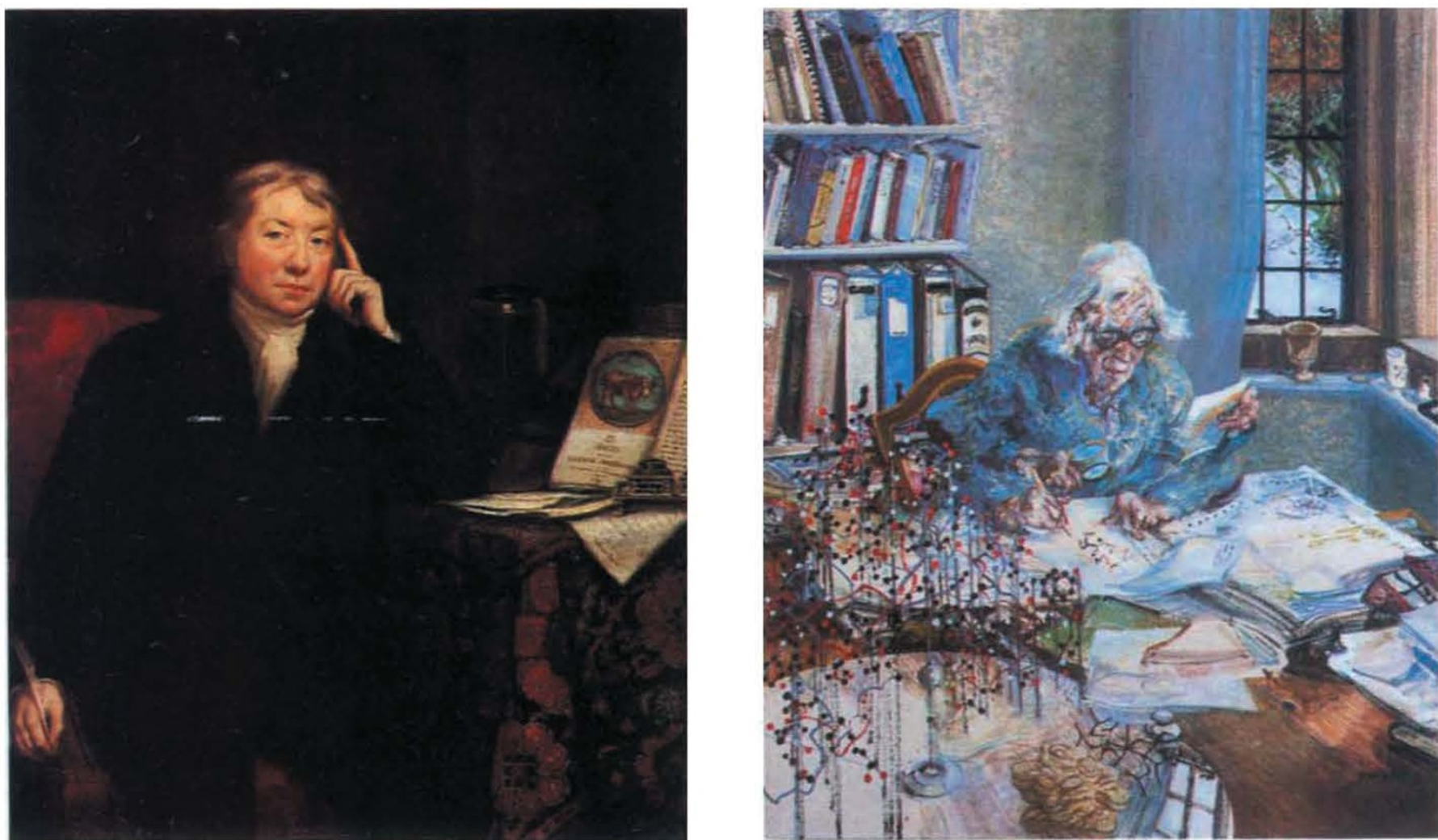

(Left) Edward Jenner (1749-1823) painted in 1802 by James Northcote. If anyone were now to try Jenner's famous experiment of 1796 they would probably find themselves in jail. He inoculated a boy with cowpox and then later with smallpox - without the latter causing iliness. Vaccination spread throughout Europe at great speed and Jenner found himself a hero: he was even able to obtain the release of English prisoners of war by a direct appeal to Napoleon. (Right) Dorothy Hodgkin painted by Maggi Hambling (1985). Some of the earliest electronic computers were put to use by Professor Hodgkin to help extract molecular structures from X-ray diffraction data. In 1949, she obtained the structure of penicillin, and in the 1950 s vitamin $B_{12}$. In 1964 she was awarded the Nobel prize.

Opening this weck at the Science Museum in London is a special exhibition "Apples to Atoms: Portraits drawn from the collections of the National Portrait Gallery". Forty-five oil paintings and drawings of distinguished British scientists from the early seventeenth century to the present day will be on display. The exhibition then moves on to Norwich, Grasmere, and Coalbrookdale.

\section{US budget}

\section{Boom time for health research}

\section{Washington}

WHATEVER the budgetary perils other agencies may face in the GrammRudman deficit-reduction era, the National Institutes of Health, Congress's perennial favourites, seem likely to come out on top of the pile once again this year. Both the Senate and the House of Representatives have voted to provide the institutes with over $\$ 6,100$ million for fiscal year 1987, which starts on 1 October, $\$ 1,000$ million more than the administration requested. The provision of extra funds to combat AIDS (acquired immune deficiency syndrome) figured prominently in debates in both houses. The increase over this year's level would be more than 15 per cent at a time when many other government agencies are facing substantial cuts.

The amount could in principle still be altered if Congress is forced to enact "sequestrations" to agency budgets this year, as it did last; but increasingly, Congressional staff seem to think it likely that a way will be found to avoid making the unpopular cuts, especially as a key provision of the Gramm-Rudman law has been found unconstitutional by the Supreme court and Congressional elections are due in November.

The House recommendation for the institutes was \$6,169 million; the Senate eventually settled on $\$ 6,117$ million, after a debate in which $\$ 47$ million was added to a committee recommendation in order to support satellite clinical trials for AIDS patients. The intention is that most or all AlDS and AIDS-related-complex patients should be able to participate in a clinical trial of one of the experimental therapies such as azidothymidine. The $\$ 47$ milion would also increase the number of AIDS treatment and evaluation units run by the National Institute of Allergy and Infectious Diseases from 14 to 19 . The total sum to be provided for the disease next year now looks likely to exceed $\$ 400$ million, almost 80 per cent more than last year.

Congress has also again made plain its displeasure with the administration's declared plan to reduce to 5,100 the number of new and competing extramural research grants awarded by the institutes; the Senate decided the figure should be not less than 6,175 grants, and the House 6,200 .

Remaining differences will be resolved in conference. L,ast year an administration bid to circumvent Congress's directives on new grants by "multi-year" funding was challenged on legal grounds, so Congress is likely to get its way.

Tim Beardsley

- No change in party. HeIN 2 , Riesenhuber. Minister in charge of the West German Federal Ministry of Research and Technology is, of course, a Christian Democrat, not a Social Democrat as written in "Industry's subsidy attacked" ( $\mathrm{Na}$ ture 323,$4 ; 1986)$. Our apologies for this error, introduced during typesetting. 